\title{
Restoring purpose: applying Biesta's three functions to the Melbourne Declaration
}

\author{
Don Carter $^{1}[0$
}

Received: 10 May 2019 / Revised: 4 August 2019 / Accepted: 12 August 2019 / Published online: 27 August 2019

(C) The Author(s) 2019

\begin{abstract}
In December 2018, the Australian Federal Minister for Education announced an impending revision of the Melbourne Declaration, the document which sets out the aims of goals of education in this nation. This is significant, given that in the current age, questions about the purposes of education appear to be continuously contested or ignored (Biesta, 2017, 2013a, 2010, 2009; Ozolinšs, 2017; Webster, 2017; Schofield, 1999; Winch, 1996; Young, 2013). Controversies including performance in standardised testing; funding; teacher quality; and pre-service teacher education dominate headlines, diverting attention from the key question which is: what are the main purposes of education? To refocus our attention, Biesta's (2009, p. 33) three purposes 'qualification', 'socialisation' and 'subjectification' - are utilised as an interpretive framework to identify the functions as embedded in the key Australian educational document: the Melbourne Declaration. As a result of this analysis, this paper advocates the use of Biesta's three purposes as an interpretive lens for the next iteration of the Melbourne Declaration to ensure attention is afforded to all three purposes, particularly subjectification.
\end{abstract}

Keywords Curriculum $\cdot$ Qualification · Socialisation · Subjectification

\section{Introduction}

The current era is one of seemingly unending contestations and controversies in education focusing on student performance in standardised tests, funding, teacher quality and the quality of pre-service teacher education. As a result, questions about the purposes and functions of education appear to be ignored (Biesta 2017; 2013a, 2010, 2009; Ozolinš 2017; Webster 2017; Schofield 1999; Winch 1996; Young 2013). These controversies divert attention from the key question: what are the functions of education? Identifying the functions of education is an important issue (Biesta 2013a, 2010, 2009; Cranston et al. 2010; Reid et al. 2010; Seddon 2015; Winch 1996), constituting an ancient tradition dating back to Confucius, Socrates, Plato and Aristotle (Schofield 1999). In

Don Carter

don.carter@uts.edu.au

1 University of Technology, PO Box 123, Broadway, NSW 2007, Australia fact, Winch (1996) contends that "setting out, clearly articulating or changing the aims of education are three of the most fundamental changes" (p. 34) that a society faces.

Accordingly, the clear articulation of the purposes of education underscores its importance because "how people learn has effects on the terms and conditions for life and the ways of being human that realise life" (Seddon 2015, p. 1). Thus, this paper is an attempt to reorientate attention to the purposes of education through an examination of the underlying purposes of education embedded in a key Australian school-based education document: the Melbourne Declaration on Educational Goals for Young Australia (Declaration) (MCYEETA 2008).

This analysis is particularly timely, given that in December 2018, the Australian Federal Minister for Education Dan Tehan announced that the Declaration will be revised in the near future. Then, on 22 February 2019 at the Education Council meeting held in Melbourne, a "special forum" of state and territory ministers and stakeholders for education, the Minister announced a review of the Declaration, which will "consider life-long education for all Australians" (2019, p. 2). Targeting "early childhood, primary and secondary schools, through to higher education, vocational training and beyond" 
(p. 2), the Minister committed to consultation with key stakeholder groups, declaring that "(o)ur children deserve a worldleading education that is tailored to their individual learning needs, and sets them up to succeed in the modern world" ( $p$. 2).

To undertake this analysis of the Declaration, I use Biesta's (2009) three purposes of education - "qualification", "socialisation" and "subjectification" (p. 33) - as an interpretive framework. The application of these purposes provides insight into the "multidimensionality of educational purpose" (Biesta 2013a, p. 128), allowing the multiple purposes of education as embedded in the Declaration. And by doing so, this analysis represents the extension of Biesta's work into an Australian context, and through using the purposes as an interpretive framework, provides new knowledge by illuminating the educational purposes inherent in the document. And while Labaree (1997) conceptualised three purposes of schooling over 20 years ago (democratic equality, social efficiency and social mobility), these purposes constitute the manifestation of "ambivalent goals" and "contradictory purposes" (p. 41), the result of government policies, rather than as the application of the purposes as an interpretive framework. Sandahl (2015) also applies Biesta's three purposes as an interpretive lens, but this is done in relation to "social studies teaching and what challenges this poses for social studies teachers" (p. 1). Thus, this paper constitutes the first time Biesta's purposes have been applied to Australian education policy.

While I expand on these three purposes later, qualification requires the individual to "do things", develop skills, knowledge and dispositions, usually for the workplace; socialisation allows the individual entry into existing social orders; while subjectification involves the individual developing a sense of self-identity, allowing her to "come into presence". And while the Declaration makes unambiguous statements about the importance and role of education, I am interested in uncovering underlying and not immediately apparent discourses embedded in the document. In addition, this paper signals the usefulness of Biesta's functions as an interpretive lens for the analysis of extant educational policy documents and as a tool for curriculum planning.

This paper delineates between the terms purposes, goals and functions of education and in doing so, distinguishes itself from some other investigations into educational approaches. For example, in his exploration of American education, Labaree (1997) uses the following terms interchangeably: "goals" (p. 40), "approaches" (p. 42) and "purposes" (p. 41). In his application of goals, he asserts that goal-setting in education is not undertaken through "a process of scientific investigation" (p. 40) but instead, focuses on the kind of schools desired, and identifies "who supports which educational values" (p. 40) forged by public debate. Winch (1996) uses the term purposes as a means by which judgements can be made about the accountability of an organisation (p. 3) which becomes the basis of agreed-to "aims" by participants, while Kelly (2009) contends that aims are usually considered as very broad statements of goals and purposes (p. 74), often considered as "too general and lacking in specificity" (p. 75). In the Melbourne Declaration, the term goals is used to identify a series of desired outcomes related to the nature of Australian schooling and the individual capacities of Australian school-aged young people but provides little detail or rationale for why the educational outcomes and capacities are important. In this paper, however, the term purpose is used as deriving from design or intention; that is, statements of broad, desired outcomes of education, embedding a rationale for why the desired outcomes are important (Elliot and Thrash 2001).

Thus, the purpose of this paper is to reveal the extent to which Biesta's (2009) three purposes of education (qualification, socialisation and subjectification) are present in the Melbourne Declaration. In doing so, I demonstrate that there is the detectable presence of socialisation and subjectification in the Declaration. Further, I argue that subjectification, in its focus on "coming into presence", strengthens the individual's capacity for empathy, the development of thoughtful capacities, perseverance and open-mindedness. The mindful interaction that subjectification encourages and the ability to act with dignity - a type of "cultivation of the self" not dissimilar to the German education tradition of Bildung - are the qualities that allow us to live as civil and responsible human beings. In addition, this research, through its application of Biesta's three purposes of education, provides an interpretive lens for future iterations of the Declaration to monitor the location and distribution of the purposes in this educational document. This application of this lens also provides the future possibility of curriculum designers utilising the three functions in the development of a school-based curriculum.

\section{Overview: The Melbourne Declaration}

The Declaration, issued by the Ministerial Council on Education, Employment, Training and Youth Affairs (MCEETYA) in 2008, provides the philosophical basis for curriculum development in each Australian state and territory. The Declaration specifies two main goals: the first of which focuses on Australian schooling to promote equity and excellence while the second goal aims at ensuring all "young Australians become successful learners, confident and creative individuals and active and informed citizens" (MCEETYA 2008, p. 7). The articulation of these national educational goals is embodied in the Australian Curriculum, comprising "a three dimensional design that includes learning 
areas; general capabilities; and three cross curriculum priorities" (Scarino 2019, p. 59).

This paper concentrates on Goal 2 of the Declaration because this specific goal focuses on the individual student as learners, as "confident and creative individuals" (MCEETYA 2008, p. 7) and as active and engaged citizens (p. 7). This focus lends itself to analysis using Biesta's three functions of education, which also have at the core, a focus on the development of personal qualities and dispositions of the individual. However, the Declaration's first goal focuses on the broad, systemic issues of education including access to quality education, equity, resources and community engagement and as such does not lend itself readily to analysis by Biesta's three functions of education.

\section{The social and political contexts of the documents}

The Declaration was developed after the election of the Labor government in 2007, an era that saw substantial changes including the initial development of the Australian Curriculum, the introduction of a national teacher accreditation scheme and what was termed the "Digital Education Revolution" (Chapman and Buchanan 2013, p. 1) through the rollout of laptops throughout Australian schools. In addition, the Declaration emerged in an era of globalisation and neoliberal thinking that had infiltrated education from the 1980s onwards (Davies and Mansell 2007), whereby neoliberal discourses manifested through an intensification of standards-driven policy and reform fuelled by the "technology of performativity" (Ball 2003, p. 216). Performativity agendas, pursued by successive Australian federal and state governments saw an increased emphasis on standardised testing programs, prescribed curricula and the development of professional teaching standards. These agendas have relied on politico-media discourses that assume an unproblematic connection between higher levels of performance in standardised tests, teacher quality and educational improvement whereby achievement in standardised tests functions as a substitution for teacher quality (Nichols and Berliner 2007) and also presume a "perfect match between educational 'input' and educational 'output"' (Biesta 2012, p. 585). A consequence of this situation is that it is not "academic knowledge and theory" (Brass 2014, p. 119) which underpins notions of excellence but rather "professional standards, free market competition, data-driven decision-making, and entrepreneurialism" (p. 119).

\section{Schooling and the declaration}

Critiques of the Declaration have investigated and identified manifestations of neoliberal thinking and policies. According to Keating (2009), Australian schooling in recent years has "increasingly become a national enterprise" (p. 51) pivotal to the "economic and social future of the nation" (p. 51). In this endeavour, the Declaration's goals provide a strong emphasis on the values underpinning schooling (p. 49) compared with previous statements of national educational goals as encapsulated in the MCEETYA (1999) and MCEETYA (1989) Declarations. Promoting an "ambitious set of goals and purposes" (Keating 2009 , p. 46) that go beyond a "human capital agenda" (p. 46), the Melbourne Declaration integrates the "principles of social inclusion and cohesion and a strong civil society" (p. 46) and "links these responsibilities to all schools" (p. 46).

Another critique of the Declaration (Moyle 2014) seeks to scrutinise its relationship to the "Australian Curriculum" and the "Australian Professional Standards for Principals and Teachers". Identifying the Declaration as a "high level vision concerning the role of Australian school education", (p. 41), it emphasises "building a democratic society" (p. 39), but fails to define "democratic values" and conflates "'democracy", 'democratic values' and 'active and informed citizens"' (p. 42). Moyle's analysis concludes that the Declaration fails to establish an "internal connection of ideas on the key themes of 'democracy' 'democratic values' and 'active and informed citizens"” (p. 42).

In their analysis, Chapman and Buchanan (2013) assert that the Declaration recognises the varied but sometimes at-odds purposes of schooling, exemplified by purposes that target "social justice, social inclusion, democratic participation, wellbeing and environmental sustainability" (p. 1) but in doing so, provide a quandary for schools: should they make a greater commitment to educational equity rather than "educational excellence" (p. 2)?. The authors argue that the Declaration emphasises a "substantial focus on the economic aims of education" (p. 1) which align with the Organisation for Economic Co-operation and Development's (OECD) focus on "people who can think creatively with knowledge, work flexibly to adapt to ever changing circumstances" ( $p$. 1). This indicates a lexicon where the "economic aims of education are given precedence amongst many other aims worthy of attention" (p. 2) which, in essence, is "an economic reform agenda under the guise of educational improvement" (p. 2) and part of a government program of "policy initiatives aimed at economic reform and achieving higher productivity and participation in the global knowledge economy" (p. 3). Further, Buchanan and Chapman (2011) argue that the Declaration is "a constellation of (sometimes contradictory) policy initiatives aimed at economic reform and achieving higher productivity and participation in the global knowledge economy" (p. 3) particularly with regard to its section on quality teaching and school leadership.

Meanwhile, Ditchburn (2012) identifies the Declaration as an example of neo-liberal discourses whereby "education is constructed as operating within a 'competitive' and 'global' 
context" (p. 263) based on "economic and/or pragmatic" reasons (p. 263). Such discourses demand that individuals are "skilled, employable workers capable of competing in, contributing to and being successful in the global economy" ( $p$. 263). As a result, other aims of education related to "human values" (p. 263) such as "respect for difference ... the role of local contexts and engagement with the community, about student and teacher agency" are marginalised.

In addition, the Declaration has been portrayed as promoting a "conceptual commitment to essentialism" (Rose 2015, p. 24 ), the philosophy underpinning curriculum design that suggests that education target "things that are essential in life" (p. 24), "a core knowledge curriculum" (p. 25) and a strong focus on the "national interest" (p. 25). Rose maps four features of essentialist philosophy against selected goals of the Declaration, showing a strong correlation between the two, as demonstrated by the following: a "belief that when society changes, so must its curriculum; the focus on the national interest; and a curriculum organised into separate subjects and set or planned by those in authority" (p. 28).

\section{Methods}

This analysis is essentially a qualitative study, drawing on aspects of document theory, the central concern of which is "what documents do, or, more properly, what is done with documents" (Buckland 2015, p. 6). Given that documents "are used to shape our culture" (p. 7) and involve human interaction with a document as a "complex series of transactions" (Gorichanaz and Latham 2016, p. 1122), we can conclude that "documents have increasingly become the means for monitoring, influencing, and negotiating relationships with others. We live in a document society." (Buckland 2015, p. 9).

More specifically, this analysis draws on the methods of content analysis which is "concerned with meanings, intentions, consequences, and context" (Downe-Wamboldt 2009, p. 314). In this approach, data are collected and with the researcher making inferences about the content in relation to a specific context (Morris and Burgess 2018, p. 109) with the approach concerning itself with the "decontextualisation, recontextualisation, categorisation and compilation of content" (p. 109). This approach centres on "meanings, intentions, consequences, and context" (Downe-Wamboldt 2009, p. 313) to ultimately reveal the focus of the "individual, group, institutional, or societal attention" (p. 313) which reflects "cultural patterns and beliefs" (p. 313). Thus, this analysis seeks to identify the underlying emphases by using Biesta's purposes of education and utilises coding through the identification and application of key words and ideas, as indicated below:

- The application of knowledge, skills, dispositions to an activity, proficiency and procedure, geared towards a specified outcome such as acquiring a job or a specific job skill (qualification). Key words and ideas which identify this purpose include workplace/employment, further study, economic goals, skills, knowledge, talents and training;

- The ways we become part of existing orders, traditions and their reproduction, relating to ways of thinking and behaving in a range of contexts (socialisation). This purpose attends to "passing on social, political and cultural values" (Sandahl 2015, p. 4). Key words and ideas which identify this purpose include culture, the transmission of traditions, values and specific behaviours including collaboration;

- The individual as being unique, exercising judgement, independence, existing with others and allowing for the opportunity to develop a "sense of self" largely through interaction with others (subjectification). Key words and ideas which identify this purpose relate to students being "able to shape their lives purposefully" (Misson 2013, p. 352 ) through the activation of personal agency, selfidentity and self-awareness.

While this interpretive framework provides an overview of the presence of each function in the Melbourne Declaration, it can be argued that a number of the statements in the Declaration are not easily categorised and may straddle two or more functions. These statements will be identified later in this paper.

\section{A brief overview of Biesta's work regarding education}

In utilising Biesta's three purposes of education, it is worthwhile to provide a brief overview of his work in education. Biesta's work has largely centred on the "relationship between education, democracy and citizenship" (Biesta n.d.) as well as the theory and philosophy of education; vocational education; adult education and lifelong learning; teachers and teaching; policy analysis; and the theory and philosophy of educational and social research. A key text, The Beautiful Risk of Education (2013a) is an exploration of seven educational concepts - creativity, communication, teaching, learning, emancipation, democracy and virtuosity - while Biesta (2010) investigates the use of the measurement of educational outcomes designed to compare the performance of education within and across countries. Here, Biesta explores why the question of what constitutes "good education" has become difficult to question to answer and shows why this has been harmful for the quality of education and for the level of democratic control over education.

In "Receiving the Gift of Teaching: From 'Learning From' to 'Being Taught By"' (2013b), Biesta distinguishes between 
learning from and taught by, arguing that the role of the teacher has been diminished to a "disposable and dispensable 'resource"" (p. 249) and maintaining that for an "understanding of teaching in terms of transcendence, where teaching brings something radically new to the student" (p. 249), the main role is to teach students actively, rather than merely facilitate student learning. Biesta is interested in resetting educational discourses by disrupting norms and practices via a "pedagogy of interruption" (Biesta 2006, p. 11), seeking to reorientate attention from the acquisition of knowledge, skills and values to a consideration of how educators can create opportunities for students to "come(ing) into the world as singular beings" (p. 27).

Central is his proposal that qualification, socialisation and subjectification constitute three functions of education, each representing "overlapping, intertwined and to a certain extent, even conflicting dimensions of what education is and can be about" (Biesta 2010, p. 26). While one function should not override the others, "the question of good education is a composite question" (Biesta 2009, p. 44). Arguing that educators need to attend to the complexities of each function and attempt to identify the "interactions between what happens in these three areas" (Biesta 2010, p. 27), he cautions that failure to engage thoughtfully with the functions exposes education to the "real risk that data, statistics and league tables" (p. 27) will direct decision-making in education.

Biesta's work, however, is not without its critics. In a review of Good Education in an Age of Measurement: Ethics, Politics, Democracy, Jörg (2011) asserts that Biesta adopts a simplistic approach by not regarding education as a "scientific problem" (p. 111) to be "treated as such, based on everevolving assumptions and intentions of those organizing education in practice" (p. 111). In doing so, Jörg alleges that Biesta demonstrates "ignorance on the topic of education" (p. 111, original italics) and fails to take into account the "common prejudices, the myopia, the learner incapacities of those involved in the field and the role of outdated and blinding paradigms" (p. 111). In addition, Jörg alleges that Biesta reveals a narrow view on education by taking the "reality of education too much for granted" (p. 113) by assuming an "ends-oriented approach instead of a possibility-oriented approach" (p. 113, original italics). This limited approach, in Jörg's eyes, disallows an "enlargement of the possible around what it means to educate and be educated" (p. 112, original italics).

It is also possible to critique Biesta's three functions of education as promoting an individualistic approach: that is, promoting the individual's uniqueness, sense of self and the right to express herself at the expense of a wider sense of "common good", the idea that the community in general provides to individual members "facilities - whether material, cultural or institutional ... in order to fulfill a relational obligation they all have to care for certain interests that they have in common" (Hussein 2018, p. 1). In fact, MacAllister (2016) argues that Biesta's "concept of subjectification presented by Biesta is elusive" (p. 375) and MacIntyre (1998) argues that students should learn to think for themselves and develop a stronger sense of the common good. While I consider these critiques worthy of further consideration, the focus of this paper is the inaugural application of Biesta's three purposes of education as an interpretive framework to the Melbourne Declaration and as such stands to offer unique insights regarding the Declaration not hitherto available through other analyses.

\section{The qualification purpose}

A key purpose of education is qualification which is largely concerned with how education "qualifies people for doing things" (Biesta 2013a, p. 128). This purpose provides the "knowledge, skills, and dispositions" (p. 147) that allow student to engage in a particular activity, proficiency or procedure, such as training for a specific job. Biesta identifies this as "one of the major functions of organised education", acting as "an important rationale for having state-funded education" and closely connected to "economic arguments" like the "preparation of the workforce", highlighting the "contribution education makes to economic development and growth" (Biesta 2009, p. 40). The significance of this purpose is apparent through ongoing dialogue between governments and employers "about the apparent failure of education to provide adequate preparation for work" (p. 40) and the "contribution education makes to economic development and growth" ( $p$. 40).

\section{The socialisation purpose}

This purpose centres on the social aspect of a student's life highlighting the "'insertion' of newcomers into existing orders" (Biesta 2013a, p. 128). More specifically, it refers to "the ways in which ... we become part of existing traditions" (p. 4) and "members of and part of particular social, cultural and political "orders"” (Biesta 2009, p. 40). Centring on the "reproduction of the established socio-political, economic, and cultural orders in the name of social cohesion, stability, and continuity" (Benhur Oral 2015, p. 212), socialisation can constitute deliberate, programmed school policies and procedures to ensure the continuation and transmission of specific values and norms, as evident in faith-based educational institutions. This encompasses the structures and processes operating in schools to "insert(ing) individuals into existing ways of doing and being" (Biesta 2009, p. 40) and even if no specific programmes promoting socialisation are developed and implemented in schools, where the "overt and intricate nexus 
between the hidden curriculum and the knowledge relayed via school dynamics" (Paraskeva 2011, p. 4) are immediately apparent, strong aspects of socialisation may still exist.

\section{The subjectification purpose}

Subjectification centres on the "idea of uniqueness" (p. 81). Based on the question "who are we?" (Ball and Olmedo 2012, p. 92), subjectification facilitates "the right to define ourselves according to our own judgments ... according to our own principles, an aesthetic of the self" (p. 92). Subjectification helps articulate how we are different from social "orders" (Biesta 2010, p. 81), allowing us to establish "independence from such orders" (Biesta 2009, p. 40). Subjectification stresses the importance of interaction with others through which our "distinct uniqueness" (Biesta 2010, p. 85) is developed and displayed; it draws attention to the "particular ways in which we exist with others." (p. 85, original italics). Biesta asserts that through action, the individual is able to "disclose" (p. 85) his or her uniqueness by demonstrating a willingness to "run the risk that our beginnings are taken up in ways that are different from what we intended" (p. 85). Subjectification allows for the development of opinions, ways of thinking and rationality as the basis for "responsible responsiveness to alterity and difference" (p. 41).

Closely allied is the notion of "coming into presence" (Biesta 2005, p. 62), requiring the individual to respond-to "take a stand" on an issue, denoting a type of existential transformation, where previously half-formed, hazy notions and opinions are able to be articulated in a way that says "here I am". The notion of "coming into presence" embraces learning "disturbances": that is, disruption to an individual's thinking that challenges, disturbs or irritates (p. 62). It requires the individual to respond to what is "different", or "other", attending to questions like "what do you think about this?", "where do you stand?" and "how will you respond?" (p. 62). This provides significant scope for the student to encounter and engage in learning experiences that allow for an emerging sense of identity and provides the opportunity for individual and collaborative responses, reflection and evaluation. The idea is predicated on engagement: saying, doing, acting, responding, listening, hearing, seeing, adopting and expressing a point of view and allowing a student to evolve into a "unique, singular being" (Biesta 2005, p. 63). Coming into presence shows strong resemblances with the German educational tradition of Bildung which, as indicated earlier, essentially refers to the "education of the self" (Løvlie and Standish 2002, p. 318) where the student's "innate powers and character development" ( $p$. 318) are strengthened.

\section{The Melbourne Declaration and the three purposes of education}

As specified above, the Declaration provides the overarching "vision" for education in Australia, and as indicated earlier, this paper focuses on the second goal which aims to develop students as "successful learners" (p. 7) because this goal specifies the individual qualities the document is seeking to develop in students. This goal has eight points relating to the following: independent learning; capacities to use Information and Communication Technologies (ICT); development of the skills to work both independently and collaboratively; literacy and numeracy skills; and success in further education. To provide an overview of the Declaration's relationship to and reflection of the three purposes of education, specific statements from the document are identified and linked to the specific purpose of education.

\section{The presence of qualification in Goal 2}

In the goal to develop "successful learners", five points reflect the qualification purpose. The first, "(develop) essential skills in literacy and numeracy" (p. 8) indicates the necessity of developing skills essential for school studies and future workplace demands. The statement that students "(are) creative and productive users of technology, especially ICT" (p. 8) also reflects this function in that skilful use of technology and ICT is closely linked to success in school and at work. In this statement, the notion of "creativity" is linked to the use of technology and ICT, reflecting the idea that "creativity within modern capitalism is especially identified with the creation of new products (... new technologies)" (Pope 2005, p. 60). Qualification is also evident in the statement that students need to "obtain and evaluate evidence in a disciplined way as the result of studying fundamental disciplines" (MCEETYA 2008, p. 8). Here, the strategic compilation and evaluation of evidence through the investigation of academic disciplines provide students with a solid platform for their school and potential tertiary studies as well as for workrelated activities. Also related is the importance of strategic and disciplined thinking that enables students to be "able to solve problems in ways that draw upon a range of learning areas and disciplines" (p. 8).

In addition, qualification is apparent in the intention that students be able to "plan activities independently" (p. 8), though this could also be argued to be related to subjectification. This capacity, valuable within school-based work, is also valuable within the workforce. In this "successful learners" goal, socialisation is apparent in the statement that students need to "collaborate, work in teams and communicate ideas" (p. 8) indicating the importance of communication, positive relationships, sharing ideas and setting goals. 
Qualification is also evident in two aims, the first of which states that through education, students "(are) enterprising, (and) show initiative" (p. 9), indicating that without personal drive and energy, the individual is less likely to experience success at school and in the workplace. The qualification purpose is also evident in the statement that students need to "pursue university or post-secondary vocational qualifications" clearly signalling the connection with formal qualifications.

\section{The presence of socialisation in Goal 2}

This goal also attends to socialisation, as evidenced by the statement that students must "develop personal values and attributes such as honesty, resilience, empathy and respect for others" (p. 9). This reflects the Kantian notion of Enlightenment where "men's (sic) release from his (sic) selfincurred tutelage ... (occurs) through the exercise of his (sic) own understanding" (Kant, 1992, cited in Biesta 2007, p. 345). This capacity assists in cultivating sensitivity and responsiveness to social contexts, social interactions and the qualities to ensure the individual is able to develop and sustain relationships. Socialisation is also apparent in statements that students "relate well to others and form and maintain healthy relationships" (MCEETYA 2008, p. 9) and "(are) well prepared for their potential life roles as family, community and workforce members" (p. 9). In addition, the statements that "(learners) collaborate, work in teams" (p. 9) and "are able to make sense of the world" point to young people engaging with others to not only "get things done" but to also provide a platform for understanding the world and its affairs.

\section{The presence of subjectification in Goal 2}

Subjectification has a strong presence in this goal. Part of Goal 2 aims to develop students as "confident and creative individuals" (MCEETYA 2008, p. 9), involving nine points related to the affective domain encompassing the following: human feelings; what we value; our appreciation, interests, motivations and attitudes. Here, the focus is on the development of "self-worth", "self-awareness" and "personal identity" (p. 9); the development of attitudes and behaviours related to honesty, respect and resilience; well-being, decision making and relationships.

The statement that students are required to "develop their capacity to learn" (p. 8) signals the importance of selfreflection and self-direction, to become "more autonomous and independent in their thinking and acting" (Biesta 2009, p. 41). Closely linked to this is the statement that students should "play an active role in their own learning" (MCEETYA 2008, p. 8). This reinforces the idea that the individual student develops autonomy to know "both what one is doing and why one is doing it" (Giddens 1991, p. 35). This goal (successful learners) reflects subjectification by ensuring students "(are) creative and resourceful" (MCEETYA, 2008 , p. 8). While creativity and resourcefulness are not limited to this purpose, both require a significant degree of selfreflection and individual strategic thinking, where resourcefulness can be seen as the "re-creation of the "old"" (Pope 2005 , p. 57) and not merely the "generation of "the novel"" (p. 57). The statement "make sense of their world" (MCEETYA 2008, p. 8) constitutes subjectification by requiring the critique of contextual phenomena and the adoption of "ways of being that hint at independence" (Biesta 2009, p. 40). Closely related to this is "(students) think about how things have become the way they are" (MCEETYA 2008, p. 8 ) where developing the capacity for deep and sustained thought and evaluation enables the student to establish a sense of how "overarching orders" (Biesta 2010, p. 81) - social, historical, cultural and personal - have eventuated and how the individual is shaped and compelled (or otherwise) by these orders.

The aim to develop "confident and creative individuals" (MCEETYA 2008, p. 8) also integrates subjectification. Here, a distinctly Aristotelian resonance is discernible where students "(have) a sense of self-worth, self-awareness and personal identity that enables them to manage their emotional, mental, spiritual and physical wellbeing" (p. 9). Flagging the capacity for contemplation-according to Aristotle, the "highest form of activity" (Aristotle et al. 1976, 1177a5-25, p. 328) - the individual attends to aspects of the self to both acknowledge and manage the contours of the inner landscape in pursuit of a contemplative "self-sufficiency" (1177a25b13, p. 329). In addition, students are to be sufficiently selfaware in order to "use their creative abilities" (MCEETYA 2008 , p. 9) as well as "(have) a sense of optimism about their lives and the future" (p. 9). Both aims require a self-awareness, reminiscent of a conception of creativity developed in the 1950 s in the USA where "humanist psychologists" (Sawyer 2012, p. 26) promoted creativity as a "form of selfdiscovery, therapy, and self-knowledge" (p. 26). The final aim relating to subjectification is that students need to "make rational and informed decisions about their own lives and accept responsibility for their own actions" (MCEETYA 2008, p. 9). This aim signals a Kantian emphasis on "rational autonomy" (Biesta, 2007. p. 27) where students can think independently and are capable of making their own judgments (p. 345).

\section{Overlapping/hybrid purposes in Goal 2}

The Declaration's next aim is that students develop into "active and informed citizens" and involves seven dot points related to attitudes and behaviours, including respect for 
others, democracy and responsibilities at the local and global levels with regard to sustainability for the natural and social environments. In this aim, the overlapping qualities of the three purposes are apparent, particularly with regard to qualification and subjectification. For example, the statement that students develop an "understanding of Australia's system of government, history and culture" (p. 9) could be argued to relate to each of the three purposes in different ways. Here, qualification is evident in that individual knowledge and understanding of these areas can be advantageous in the workplace, while understanding of these areas can be argued to provide "easy access" into "existing ways of doing and being" (Biesta 2009, p. 40). Also overlapping are the following statements: "understand and acknowledge the value of Indigenous cultures" (MCEETYA 2008, p. 9); "possess the knowledge, skills and understanding to contribute to, and benefit from, reconciliation between Indigenous and non-Indigenous Australians" (p. 9); "participate in Australia's civic life" (p. 9); and "are able to communicate across cultures" (p. 9); "act with moral and ethical integrity" (p. 9); "appreciate Australia's social, cultural, linguistic and religious diversity" (p. 9); "work for the common good, in particular sustaining and improving natural and social environments" (p. 9); "(are) responsible global and local citizens" (p. 9); "are committed to national values of democracy, equity and justice" (p. 9).

These statements indicate two types of literacies: "political literacy", required for citizenship; and "cultural literacy" (Biesta 2009, p. 40) where students acquire the "knowledge and skills considered necessary to for functioning in society more generally" (p. 40) involving being able to recognise and acknowledge past and existing "social, cultural and political "orders" (p. 40). Further, the statements bring to mind Arendt's notion of impartiality where "'taking the viewpoints of others into account' is its defining characteristic" (Taylor 2002, p. 161). This involves Arendt's notion of "enlarged thinking" (p. 162) where the individual is able to "look upon, to watch, to form judgments or ... to reflect upon human affairs" (p. 162) transforming into a "world citizen" (p. 162).

\section{Discussion of the three purposes in relation to Goal 2}

This analysis seeks to illuminate the underlying educational purposes of Goal 2 of the Declaration by identifying the presence of Biesta's three purposes of education. The Declaration's two broad goals serve to frame students broadly as learners, individuals and future citizens, acknowledging the intricacies of their lives within and beyond school and in the future workplace. It promotes a "holistic view of education" (Buchanan and Chapman 2011, p. 11) where the "intellectual, physical, moral spiritual and aesthetic development" (p. 11) of the students is paramount while recognising that each individual is a multidimensional and complex social being living and interacting with a range of other individuals and groups.

While analyses of the Declaration have identified neoliberal discourses as specified above, an examination of the Declaration's relationship to and reflection of the three purposes show coverage of each, particularly the qualification and subjectification purposes. Based on this analysis, it is possible to conclude that the Declaration assigns value to each of these purposes, recognising that each has a significant role in education and in the development of individual dispositions of the student. This is, however, not to say that there are no possible improvements to be made to the Declaration. And in addition, we need to be careful that the application of the three purposes does not diminish its use to that of a checklist: one that merely identifies the inclusion of educational purpose, idea or concept without offering the opportunity to delve deeply into the essence of those embedded ideas. Thus, if we use the three purposes as an interpretive tool, we are able to interrogate the Declaration not only to detect the presence or otherwise of an idea or concept but to also investigate the depth of those ideas or concepts.

And by means of illustration, the Declaration's series of well-meaning statements on educational outcomes, such as "(students) participate in Australia's civic life" (MCEETYA 2008, p. 9), provides a sense of what is considered as highly desirable. However, the Declaration is silent about why these are worthy ideals and what they mean. Here, a revision of the document could more strongly acknowledge that schools are part of a wider community and that students, as individuals or in groups, are able to enact different forms of "civic duty", whether this be through working with groups and individual members of the community, such as a school musical band visiting the local retirement village or a school opening its doors for a "Grandparents' Day". Here, I am not advocating for the inclusion of a list of activities, but rather, the recalibration of the purposes of schooling that could capture a stronger sense of why the purpose is important and how a purpose might be realised. And in doing so, the strengthening of the idea of the common good - for all Australians - as well as a detailing of the development of individual student qualities and dispositions could well be realised. Thus, a revision of the structure and nomenclature of the document is also required including the relocation of the importance of community partnerships to a more prominent part of the document and the retitling of goals as purposes to provide not only the sense of direction but also the rationale underpinning the purpose.

As discussed above, the Declaration embeds the three purposes throughout Goal 2. What is important to remember here is that, and as indicated above, the Melbourne Declaration "provides the policy framework for the Australian Curriculum" (ACARA n.d.), the national, authorised school-based curriculum of Australia. This means the scope, depth and nature of the purposes of education, as specified in the Declaration, dictate the 
national curriculum in its breadth, depth, aims and content. And while it is beyond the scope of this paper to engage with the wide range of critiques of the Australian curriculum (e.g. Batiste et al. 2015; Briant and Doherty 2012; Ditchburn 2012; Yates et al. 2011), Scarino (2019) comments that this curriculum is "no more than a three-dimensional structure or an architectural design, with no indication given as to why the shape is as it is and how exactly the elements might be fleshed out in conceptually rich ways" (pp. 62-63). This observation identifies a significant structural challenge for teachers implementing the national curriculum. And when we consider the different levels of curriculum interpretation - at the school systems, whole school and individual teacher levels - we must attend to the likelihood that a myriad of possible complications extant in a practitioner's classroom may thwart, retard or reshape the interpretation and articulation of the intentions and sentiments of the Declaration because classroom teachers act as "avid curriculum mediators" (Briant and Doherty 2012, p. 1) in the transformation of the pre-active into the "enacted curriculum" (Porter 2001, p. 2), working within a multitude of competing priorities at the school level including school-based and external assessment regimes and co-curricular responsibilities, as well as administrative and accountability responsibilities.

\section{Conclusion}

This paper highlights the underlying purposes of education in the Declaration by using Biesta's (2009) three purposes as an interpretive lens. Some degree of comfort might well be gleaned from the results of this analysis in that there is the discernible presence of socialisation and subjectification in the Declaration which (to a degree) mitigate against the presence of neoliberal discourses identified above. Goodson and Gill (2014) argue that when learning is reduced to the acquisition of employability skills - as captured in the qualification purpose - "people are treated as economic objects" (p. 42), reducing their capacity for positive social interaction and fulfilling relationships. Further, it can be argued that subjectification in particular, in its focus on coming into presence, strengthens the individual's tendency towards compassion, the development of contemplative capacities, perseverance and open-mindedness. The mindful interaction that subjectification encourages, in addition to the ability to act with dignity - a type of "cultivation of the self" akin to Bildung, where reasoned, thoughtful actions form the basis of interactions with others - are the qualities which make us human and allow us to live harmoniously amongst each other.

Therefore, this paper advocates using Biesta's (2009) three functions as an interpretive lens for the next iteration of Australia's national goals for schooling. By using this lens, attention is afforded to the distinct emphases of each purpose, thus identifying the degree to which purpose is to be accentuated in the revised document and potentially avoiding an imbalance and overstatement of one or more of the purposes and potentially skewing the focus of Australia's aims and goals of education. And at the local level, the utilisation of the three purposes also provides an interpretive lens for the design of future school-based curriculum to ensure that curriculum writers are aware of the distribution and location of the purposes across the curriculum.

Open Access This article is distributed under the terms of the Creative Commons Attribution 4.0 International License (http:// creativecommons.org/licenses/by/4.0/), which permits unrestricted use, distribution, and reproduction in any medium, provided you give appropriate credit to the original author(s) and the source, provide a link to the Creative Commons license, and indicate if changes were made.

\section{References}

Aristotle, Thomson, J. A. K., \& Tredennick, H. (1976). The ethics of Aristotle: the Nicomachean ethics. Harmondsworth: Penguin.

Australian Curriculum Assessment \& Reporting Authority. (n.d.). Retrieved: https://www.australiancurriculum.edu.au/resources/ student-diversity/. Accessed 30 Apr 2019

Ball, S. J. (2003). The teacher's soul and the terrors of performativity. Journal of Education Policy, 18(2), 215-228.

Ball, S. J., \& Olmedo, A. (2012). Care of the self, resistance and subjectivity under neoliberal governmentalities. Critical Studies in Education, 54(1), 85-96.

Batiste, W., Walker, S., \& Smeed, J. (2015). The relationship between teachers' perceptions of school leadership and their perceptions of the implementation of the national curriculum. Leading and Managing, 21(1), 69-85.

Benhur Oral, S. (2015). Complicating Gert Biesta's account of subjectification: Žižekian negativity and Buddhist Śūnyatā. Interchange, 47, 211-227.

Biesta, G. J. J. (2005). Against learning. Reclaiming a language for education in an age of learning. Nordisk Pedagogik, 25, 54-66.

Biesta, G. J. J. (2006). Beyond learning: democratic education for a human future. Boulder: Paradigm Publishers.

Biesta, G.J.J. (2007). The education-socialisation conundrum or 'Who is afraid of education?. Utbildning \& Demokrati, (3), 25-36.

Biesta, G. J. J. (2009). Good education in an age of measurement: on the need to reconnect with the question of purpose in education. Educational Assessment, Evaluation and Accountability, 21(33), 33-46.

Biesta, G. J. J. (2010). Good education in an age of measurement. London: Routledge.

Biesta, G. J. J. (2012). Philosophy of education for the public good: five challenges and an agenda. Educational Philosophy and Theory, 44(6), 581-593.

Biesta, G. J. J. (2013a). The beautiful risk of education. Boulder Co: Paradigm Publishers.

Biesta, G. J. J. (2013b). Receiving the gift of teaching: from "learning from" to "being taught by". Studies in Philosophy and Education, $32(5), 449-461$.

Biesta, G. J. J. (2017). Education, measurement and the professions: reclaiming a space for democratic professionality in education. Educational Philosophy and Theory, 49(4), 315-331.

Biesta, G. (n.d.). Retrieved from https://www-gertbiesta-com.jimdosite.com/. Accessed 1 June 2019.

Brass, J. (2014). English, literacy and neoliberal policies: mapping a contested moment in the United States. English Teaching: Practice and Critique, 13(1), 112-133. 
Briant, E., \& Doherty, C. (2012). Teacher educators mediating curricular reform: anticipating the Australian Curriculum. Teaching Education, 23(1), 51-69.

Buchanan, R., \& Chapman, A. (2011). Utopia or dystopia? - A critical examination of the Melbourne Declaration (pp. 1-13). New Zealand: Philosophy of Education Society of Australasia.

Buckland, M.K. (2015). Document theory: an introduction. Records, archives and memory: selected papers from the conference and school records, archives and memory studies, University of Croatia, May 2013. Zadar: University of Zadar, 1-10.

Chapman, K., \& Buchanan, R. (2013). Opinion: Educational purposes and the Melbourne Declaration. Professional Educator, 12(5), 25-27.

Cranston, N., Kimber, M., Mulford, B., Reid, A., \& Keating, J. (2010). Politics and school education in Australia: a case of shifting purposes. Journal of Educational Administration, 48(4), 182-195.

Davies, B., \& Mansell, P. (2007). Neoliberalism and education. International Journal of Qualitative Studies in Education, 20(3), 182-195.

Ditchburn, G. (2012). A national Australian curriculum: in whose interests? Asia Pacific Journal of Education, 32(3), 259-269.

Downe-Wamboldt, B. (2009). Content analysis: method, applications, and issues. Health Care for Women International, 13(3), 313-321.

Elliot, J. A., \& Thrash, T. M. (2001). Achievement goals and the hierarchical model of achievement motivation. Educational Psychology Review, 13(2), 139-156.

Giddens, A. (1991). Modernity and self-identity. California: Stanford University Press.

Goodson, I., \& Gill, S. (2014). Critical narrative as pedagogy. London: Bloomsbury.

Gorichanaz, T., \& Latham, K. F. (2016). Document phenomenology: a framework for holistic analysis. Journal of Documentation, 72(6), $1114-1133$

Hussein, W. (2018). The common good. Stanford encyclopaedia of philosophy. Retrieved: https://plato.stanford.edu/entries/commongood/. Accessed 2 Aug 2019.

Jörg, T. (2011). A review of good education in an age of measurement: ethics, politics, democracy. Complicity: An International Journal of Complexity and Education, 8(2), 110-116.

Keating, J. (2009). A new federalism in Australian education: a proposal for a national reform agenda. Education Foundation. Retrieved from https://www.fya.org.au/app/theme/default/design/assets/ publications/fya_newfederalism_fullreport2.pdf. Accessed 28 Nov 2018.

Kelly, A.V. (2009). The Curriculum. Theory and Practice. 6th edition, Sage Publications: London.

Labaree, D. F. (1997). Public goods, private goods: the American struggle over educational goals. American Educational Research Journal, 34(1), 39-81.

Løvlie, L., \& Standish, P. (2002). Bildung and the idea of a liberal education. Journal of Philosophy of Education, 36(3), 317-340.

MacAllister, J. (2016). What should educational institutions be for? British Journal of Educational Studies, 64(3), 375-391. https://doi. org/10.1080/00071005.2015.1131811.

MacIntyre, A. (1998). Politics, philosophy and the common good. In K. Knight (Ed.), The MacIntyre reader. Cambridge: Polity Press.

Ministerial Council on Education, Employment, Training and Youth Affairs. (1989). Common and Agreed Goals for Schooling in Australia. Canberra. Retrieved from: http://www.mceetya.edu.au/ mceecdya/hobart_declaration, 11577.html.

Ministerial Council on Education, Employment, Training and Youth Affairs. (1999). The Adelaide Declaration on National Goals for Schooling in the Twenty First Century. Canberra. Retrieved from: http://www.dest.gov.au/sectors/school_education/policy_ initiatives review.

Ministerial Council on Education, Employment, Training and Youth Affairs. (2008). Melbourne declaration on educational goals for young. [online] Melbourne: Ministerial Council on Education,
Employment, Training and Youth Affairs. Retrieved from http:// www.curriculum.edu.au/verve/ resources/national declaration on the educational goals for_young australians.pdf.

Misson, R. (2013). The problem of agency: posthumanist theory and English teaching. Changing English: Studies in Culture and Education, 20(4), 351-363.

Morris, A., \& Burgess, C. (2018). The intellectual quality and inclusivity of Aboriginal and Torres Strait Islander content in the NSW stage 5 history syllabus. Curriculum Perspectives, 38, 107-116.

Moyle, K. (2014). Technologies, democracy and digital citizenship: examining Australian policy intersections and the implications for school leadership. Education in Science, 4, 36-51.

Nichols, S. L., \& Berliner, D. C. (2007). Collateral damage: how highstakes testing corrupts America's schools. Harvard: Harvard University Press.

Ozolinšs, J. T. (2017). Creating a civil society east and west: relationality, responsibility and the education of the humane person. Educational Philosophy and Theory, 49(4), 362-378.

Paraskeva, J. M. (2011). Conflicts in curriculum theory: challenging hegemonic epistemologies. New York: Palgrave Macmillan.

Pope, R. (2005). Creativity, theory, history, practice. New York: Routledge.

Porter, A. (2001). Defining, developing, and using curriculum indicators. CPRE Research Reports. Retrieved from http://repository.upenn. edu/cpre_researchreports/69.

Reid, A., Cranston, N., Keating, J., \& Mulford, B. (2010). Exploring the public purposes of education in Australian primary schools. Report of an ARC Linkage Project. Australian Government Primary Principals Association. Retrieved from https://www.aare.edu.au/ data/publications/2009/cra09995.pdf. Accessed 28 Nov 2018

Rose, J.R. (2015). The Australian curriculum: perspectives of teachers and school administrators on issues and concerns surrounding implementation. Thesis submitted November, 2015 to the Faculty of Arts, University of Adelaide.

Sandahl, J. (2015). Social studies as socialisation, qualification and subjectification. Montreal, Canada: Paper presented at the panel "Citizens still in School: Motivations for Political Participation ECPR General Conference Retrieved from https://ecpr.eu/Filestore/ PaperProposal/4ec2404c-b72f-410b-b1bd-e4f96eb34205.pdf. Accessed 28 Nov 2018

Sawyer, R. K. (2012). The science of human innovation. Explaining creativity. New York: Oxford University Press.

Scarino, A. (2019). The Australian curriculum and its conceptual bases: a critical analysis. Curriculum Perspectives, 39, 59-65.

Schofield, K. (1999). The purposes of education 3. Consultation Paper. Brisbane: Queensland Department of Education.

Seddon, T. (2015). Das Argument: Zeitschrift fuer Philosophie und Sozialwissenschaften, 314(57), 565-575.

Taylor, D. (2002). Hannah Arendt on judgment: thinking for politics. International Journal of Philosophical Studies, 10(2), 151-169. https://doi.org/10.1080/0967255021021531.

Webster, R. S. (2017). Valuing and desiring purposes of education to transcend miseducative measurement practices. Educational Philosophy and Theory, 49(4), 331-346.

Winch, C. (1996). The aims of education revisited. The Journal of the Philosophy of Education, 30(1), 33-44.

Yates, L., Collins, C., O'Connor, K. (Eds.). (2011). Australia's curriculum dilemmas: state cultures and the big issues. Carlton: Melbourne University Press

Young, M. (2013). Overcoming the crisis in curriculum theory: a knowledge-based approach. Journal of Curriculum Studies, 45(2), 101-118. https://doi.org/10.1080/00220272.2013.764505.

Publisher's note Springer Nature remains neutral with regard to jurisdictional claims in published maps and institutional affiliations. 